\title{
SEARCH FOR NEW ANTILEISHMANIAL CHEMOTHERAPEUTICS
}

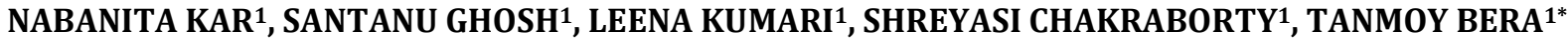 \\ ${ }^{1}$ Laboratory of Nanomedicine, Division of Pharmaceutical Biotechnology, Department of Pharmaceutical Technology, Jadavpur \\ University, Kolkata 700032, India \\ Email: proftanmoybera@gmail.com
}

Received: 20 Jun 2017 Revised and Accepted: 22 Nov 2017

\begin{abstract}
Objective: The objective of this work was to screen a number of compounds for their antileishmanial efficacy and cytotoxicity profiling

Methods: Curry leaf oil, cypress oil and spikenard oil were identified by gas chromatography-mass spectrometry (GC/MS) analysis. Betulinic acid, spikenard oil, cypress oil and curry leaf oil were evaluated for their in vitro antileishmanial activity against Leishmania donovani AG83 wild-type, sodium stibogluconate resistant (SSG-resistant), paromomycin (PMM-resistant) and GE1 field type strains on axenic and cellular amastigote model and compared the results with standard drugs used to treat leishmaniasis.
\end{abstract}

Results: Betulinic acid showed strong antileishmanial activity against wild-type (SI= 192.8), SSG-resistant (SI= 19.3) and GE1 strains (SI= 100), whereas cypress oil has produced highest antileishmanial activity against PMM-resistant strains (SI=15.09) among all the tested drugs. The data obtained also revealed that cypress oil had the maximum $\mathrm{CC}_{50}$ value of $452.9 \mu \mathrm{l}$ among all standard and tested drugs.

Conclusion: All tested drugs had antileishmanial property but among them, betulinic acid possess strong antileishmanial activity in case of both wild-type and drug-resistant leishmaniasis.

Keywords: Betulinic acid, Spikenard oil, Cypress oil, Curry leaf oil, GC/MS, In vitro antileishmanial activity

(C) 2018 The Authors. Published by Innovare Academic Sciences Pvt Ltd. This is an open access article under the CC BY license (http://creativecommons.org/licenses/by/4.0/) DOI: http://dx.doi.org/10.22159/ijpps.2018v10i1.20859

\section{INTRODUCTION}

Leishmaniasis is a vector-borne parasitic disease caused by a protozoan parasite of the genus Leishmania [1]. The parasite is generally transmitted to human beings by the bite of a previously infected phlebotomine sandfly. The parasite of the disease occurs in two distinct forms: the flagellated, extracellular promastigotes that resides in the gut of female sandfly vector; and the nonflagellated, nonmotile amastigote form that exists and multiplies within the phagolysosomal compartment of macrophages [2, 3]. Depending on the causative species involved, human leishmaniasis may manifest in various forms that include cutaneous leishmaniasis (CL) mucocutaneous leishmaniasis (MCL), diffused cutaneous leishmaniasis (DCL), and visceral leishmaniasis (VL), of which visceral leishmaniasis is the most lethal form of disease caused by the species of Leishmania donovani [4].

Pentavalent antimonials such as meglumine antimoniate (Glucantime, Sanofi-Aventis) and sodium stibogluconate (Pentostan, GlaxoSmithKline) are variably effective against both VL and CL and may be administered via intravenous (IV), intramuscular (IM) or intralymphatic (IL) route. Unfortunately, the increased risk of cardiotoxicity, nephrotoxicity and widespread antimonial resistance has limited their use [5]. Recently, four new potential therapies are developed for the treatment of $\mathrm{VL}$, such as an amphotericin B liposomal formulation (AmBisome), oral miltefosine, a parenteral formulation of aminosidine (paromomycin), and oral sitamaquine. However, individual users of these drugs have several drawbacks [6]. According to recent clinical studies, combination therapies possess potential benefits against VL in India, in which short-course multidrug treatment is compared with standard therapy [7]. Nevertheless, inadequate mode of administration of current therapies, resistance and cost-related issues have prevented their widespread use. Therefore, it is imperative to develop new antileishmanial compounds with reduced side effects and toxicity. The terpenoids also referred to as terpenes obtained from the plants might be an alternative source of potent new molecules for the treatment of several critical diseases since they are a rich source of therapeutically active constituents $[8,9]$.
The genus Cupressus (commonly known as Cypress), belonging to the family Cupressaceae [10] is traditionally known to possess several beneficial activities for the treatment of stomach ache, toothache, diabetes, inflammation, laryngitis and as astringent and contraceptive $[11,12]$. Murraya koenigii, commonly known as 'Curry patta' in India, belongs to the member of family Rutaceae. Traditionally, the plant has been found to exhibit potent antioxidant [13], antimicrobial [14], hypoglycemic [15], antidiarrhoeal [16], hepatoprotective [17], melanogenesis inhibitory [18], antiobesity and lipid-lowering [19] activities. Spikenard, also known as 'Muskroot' is a class of aromatic amber-coloured essential oil obtained from the dried roots and rhizomes of a flowering plant Nardostachys jatamansi, belonging to the Valerian family [20]. Traditionally, the roots of jatamansi exhibited antimicrobial [21], antioxidant and anticholinesterase activity [22], anxiolytic [23], neuroprotective [24], anticancer [25], anti-diabetic [26] and antiandrogenic [27] activity. Betulinic acid (3- $\beta$-hydroxy-lup-20(29)-en28-oic acid) is a pentacyclic lupane-type triterpene obtained from various plants such as Tryphyllum peltatum, Ancistrocladus heyneaus, Diospyros leucomelas, Tetracera boliviana, Zizyphus joazeiro, Syzygium formosanum, etc. [28]. It exhibits a wide range of biological activities which includes antibacterial [29], antiprotozoal [30], antiviral [31], anticancer [32], anti-inflammatory and immunemodulatory [33], and anti-HIV [34] activity.

Based on the significant biological activities and medicinal properties of several bioactive terpenoids, our present study was aimed to investigate the in vitro antileishmanial properties and toxicity profile of few selected terpenoids, which include cypress oil, spikenard oil, curry leaf oil, betulinic acid and to compare their activity against some conventional antileishmanial agents like amphotericin B, sodium stibogluconate (SSG), paromomycin (PMM) and miltefosine.

\section{MATERIALS AND METHODS}

\section{Chemicals and reagents}

Curry leaf oil (CAS no. 8008-52-4) was procured from Mother Herbs Pvt. Itd. (India), Spikenard oil (CAS no. 8022-22-8) was procured 
from Aromatic and Allied Chemicals (India), Cypress oil (CAS no. 8013-86-3) and betulinic acid (CAS no. 472-15-1) were purchased from Sigma-Aldrich (India). Sodium stibogluconate was a generous gift from Albert David Ltd. (Kolkata, India). Amphotericin B (CAS no. 1397-89-3), paromomycin (CAS no. 1263-89-4) and miltefosine (CAS no. 58066-85-6) were procured from Sigma-Aldrich (India). All solvents used in the experiment were of analytical grade.

\section{Methods}

\section{Ethics statement}

BALB/c mice (20-25 g) of either sex were used to carry out the experiments. Jadavpur University Animal Ethics Committee (AEC/PHARM/1403/2014) has approved the experimental protocols. The procedures were followed in accordance to the committee's guidelines. Animals were kept in polypropylene cages and fed with standard diet and water ad libitum. Animals were exposed to a normal day and night cycle.

\section{Identification of oils by gas chromatography-mass spectro- metry (GC/MS)}

Curry leaf oil, cypress oil and spikenard oil were evaluated for the identification of chemical constituents present in them by GC/MS analysis [35]. GC/MS (Thermo Fisher Scientific India Pvt. Ltd.; model: POLARISQ) analysis was performed using ion-trap technology having electron ionization detector with the energy of 70 $\mathrm{eV}$. Helium (He) was used as a carrier gas. Data was acquired by xcalibar software.

\section{Parasite culture}

VL isolated Leishmania donovani AG83 (MHOM/IN/83/AG83) was acquired as a gift from Indian Institute of Chemical Biology, Council of Scientific and Industrial Research, Kolkata, India. According to Roy et al. [36], the parasite, Leishmania donovani AG83 promastigotes were allowed to grow in the medium 199 supplemented with $10 \%$ heat-inactivated fetal bovine serum, 20 mmol HEPES, $2 \mathrm{mmol}$ L-glutamine, $100 \mathrm{U} / \mathrm{ml}$ penicillin and 100 $\mu \mathrm{g} / \mathrm{ml}$ streptomycin at room temperature.

The axenic amastigotes were derived from promastigotes in MMA/20 (Medium for axenic amastigote), pH 5.5 culture medium. Developed axenic amastigotes were maintained by sub-culturing of $10^{5}$ parasites $/ \mathrm{ml}$ in every five days under $5 \% \mathrm{CO}_{2}$ incubator at $37^{\circ} \mathrm{C}$.

\section{Development of drug-resistant amastigote strains}

According to the Das et al. [37], drug-resistant strains of $\mathrm{L}$ donovani amastigotes were developed. Briefly, in the presence of drug concentrations respective of their $\mathrm{IC}_{50}$ values of the strain, the promastigote cells were cultured in medium 199 with required supplements. The drug concentrations were increased after three subcultures. The concentrations were increased in such a manner that the population of the promastigote cells was decreased by $20 \%$ for each batch. At the time point when $10 \%$ promastigote cells were survived, the strains were cultured on medium 199 agar plates in the presence of a similar concentration of drugs. The generated strains were then cultured in medium 199 liquid media. After that drug pressure was removed slowly and stability was checked at different time points.

\section{Drug sensitivity study}

Drug sensitivity to axenic amastigote study was done by determining the $50 \%$ inhibitory concentration $\left(\mathrm{IC}_{50}\right)$ of selected drugs. So, the $\mathrm{IC}_{50}$ values suggest that it was the concentration where $50 \%$ cells of the total population were inhibited. RI is an index which can be calculated as $\mathrm{IC}_{50}$ of a drug for a particular strain/IC $\mathrm{IC}_{50}$ of that drug for the wild-type strain. To perform the study, a pre-counted amastigote cells $\left(1 \times 10^{5}\right.$ amastigotes $\left./ \mathrm{ml}\right)$ of wild-type, drug-resistant and field isolates were seeded at 96 culture plate. Different concentrations of drugs were added to the respective wells and the well plate was kept in the $5 \% \mathrm{CO}_{2}$ incubator for $72 \mathrm{~h}$. After that cell counts were taken using hemocytometer under an inverted microscope. Numbers of amastigotes of untreated controls were compared with the drug treated wells to determine the IC 50 values [38].

\section{Drug sensitivity assay of axenic amastigote in macrophages}

Mice peritoneal macrophages were isolated by the similar technique adopted in our previous work [39]. For this study, sterile coverslips were kept in each well of the culture plate. 0.5 $\mathrm{ml}$ of RPMI-1640 media having isolated macrophage cells at a concentration of $4 \times 10^{5}$ cells $/ \mathrm{ml}$ were added to each well.

Then $0.5 \mathrm{ml}$ of medium containing axenic amastigotes were added to the wells so that the ratio between the macrophage to amastigotes should be $1: 10$ and kept into the $5 \% \mathrm{CO}_{2}$ incubator at $37{ }^{\circ} \mathrm{C}$ for $4 \mathrm{~h}$. After the internalization period, the old media was replaced with fresh RPMI-1640 medium with or without drug at the predetermined concentrations in triplicate wells. Then well plates were kept into $5 \% \mathrm{CO}_{2}$ incubator at $37^{\circ} \mathrm{C}$ for 72 h. After $72 \mathrm{~h}$, the medium was decanted and the coverslips were removed, fixed on the glass slides and air dried. Before counting the amastigotes in 100 macrophage cells, Giemsa staining was done. Results were calculated by comparing the number of amastigotes in 100 macrophage cells in treated and untreated control.

\section{Cytotoxicity assay and selectivity index}

Cytotoxicity of macrophage cells to the drugs were represented as $\mathrm{CC}_{50}$ values. $\mathrm{CC}_{50}$ is the concentration in which $50 \%$ of the macrophage cells were killed or damaged in respect of the total population of macrophage cells. The experiment was carried out in 96-well culture plates in presence of RPMI-1640 medium with supplements. The wells were seeded and predetermined concentrations of drugs were given to the respective wells and the viable macrophages were counted under an inverted microscope using hemocytometer.

The antileishmanial potency of the drugs was evaluated by the selectivity index (SI). The parameter SI is considered as the highest exposure of the drug that will not result in any toxicity to that particular exposure and produces the preferred efficacy [40]. The selectivity indexes of the drugs are determined as $\mathrm{CC}_{50}$ of the drugs in macrophages $/ \mathrm{IC}_{50}$ of the drugs against cellular amastigotes. It is assumed that drug would have the promising activity when the SI value is $\geq 10$ [41].

\section{Statistical analysis}

Experimental data were expressed as mean \pm standard deviation. Student t-test was used to calculate the statistical significances. Differences were considered to be significant when $p<0.01$ and $p>0.05$ was considered to be statistically not significant.

\section{RESULTS}

Curry leaf oil, cypress oil and spikenard oil were evaluated for the identification of the potential components by GC/MS analysis. Table 1 revealed the identified components. From fig. $1 \mathrm{~A}$ it was found that the curry leaf oil possessed 21 numbers of components present in it where 5 components were chemically identified.

They were linalool, $\beta$-ocemene, Allo-ocemene, $\alpha$-terpene and geranyl acetate. From fig. 1B it was observed that cypress oil possessed 25 components where 3 components were chemically identified which were $\alpha$-terpinyl acetate, D-3-carene and $\alpha$-carene and from fig. 1C it was found that spikenard oil possessed 32 components where 5 components were chemically identified and they were aristolene, $\beta$-patchoulene, D-cadinene, $\alpha$-cadinol and $\beta$ gurjunene.

The resistance selection process by increasing the drug pressure in a stepwise manner for AG83-resistant phenotype was found to be restrictive at $35 \mathrm{mg} \mathrm{Sb}(\mathrm{V}) / \mathrm{ml}$ for SSG and $164 \mathrm{mmol}$ for PMM when $10 \%$ viable cells among the total cell population was observed in comparison to untreated controls. 

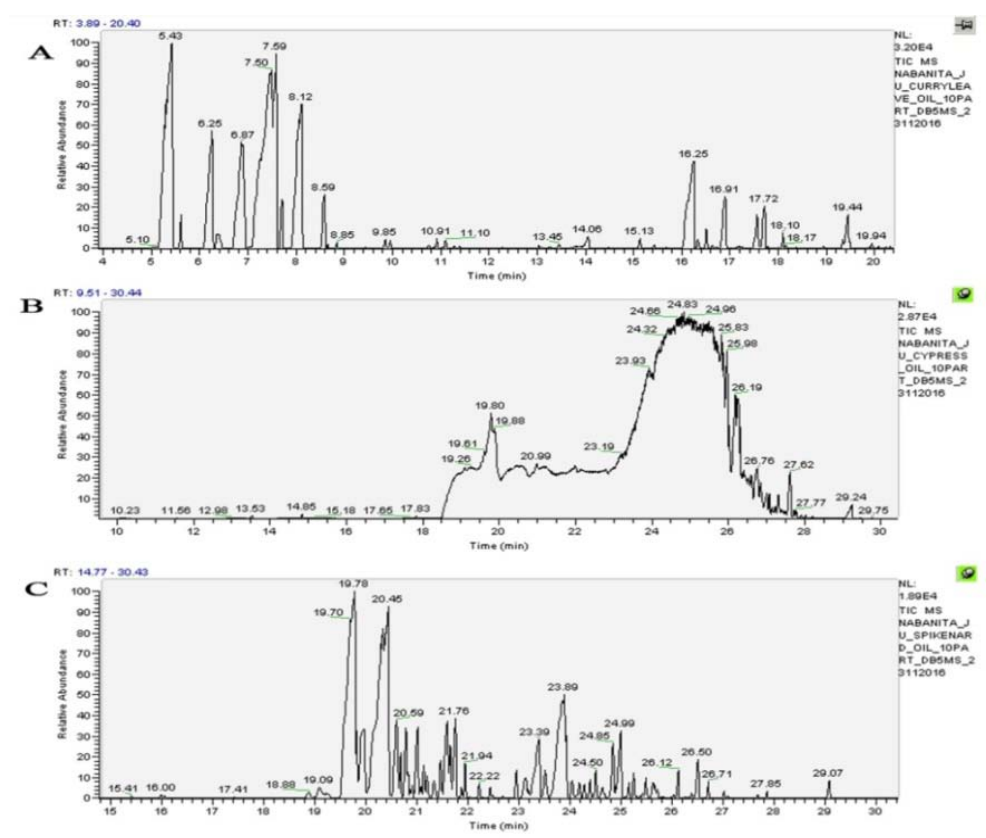

Fig. 1: GC/MS analyses of (A) curry leaf oil, (B) cypress oil and (C) spikenard oil. RT= retention time

Table 1: Identification of compounds from curry leaf oil, cypress oil and spikenard oil by GC/MS analysis

\begin{tabular}{|c|c|c|c|c|c|c|c|c|}
\hline Curry leaf oil & & & Cypress oil & & & Spikenard oil & & \\
\hline Competents & $\begin{array}{l}\text { RT }^{*} \\
\text { (min) }\end{array}$ & $\%$ peak area & Competents & $\begin{array}{l}\text { RT }^{*} \\
\text { (min) }\end{array}$ & \% peak area & Competents & $\begin{array}{l}\mathrm{RT}^{*} \\
\text { (min) }\end{array}$ & $\%$ peak area \\
\hline Linalool & 5.46 & 21.16 & $\alpha$-terpinyl acetate & 24.02 & 1.94 & Aristolene & 19.85 & 22.76 \\
\hline$\beta$-ocemene & 5.63 & 0.61 & D-3-carene & 24.85 & 21.35 & $\beta$-patchoulene & 20.01 & 4.14 \\
\hline Allo-ocemene & 6.46 & 0.78 & $\alpha$-carene & 25.92 & 6.12 & D-cadinene & 20.46 & 24.53 \\
\hline$\alpha$-terpene & 6.95 & 8.82 & - & - & - & $\alpha$-cadinol & 20.65 & 3.37 \\
\hline Geranyl acetate & 7.61 & 32.55 & - & - & - & $\beta$-gurjunene & 26.14 & 0.54 \\
\hline
\end{tabular}

${ }^{*} \mathrm{RT}=$ Retention time

When the adequate growth of the resistant strain was achieved, promastigotes were transformed to amastigotes and the IC $\mathrm{C}_{50}$ values of parent and the resistant-strain were compared to reveal the significant differences among them. Table 2 showed that SSG was resistant at about 35 to 40 fold for AG83-resistant strain, whereas, it showed about 27 to 31 fold for PMM resistance.

In case of field isolate GE1 strain, it showed 3.52 fold SSG resistance and 2.25 fold PMM resistances. Table 4 revealed interesting results, where the test drugs spikenard oil and curry leaf oil showed minimal and similar resistance index for both the resistant strains. However, betulinic acid showed higher resistance against SSG resistant strain (RI= 10.6) and PMM resistant strains $(\mathrm{RI}=23.9)$.

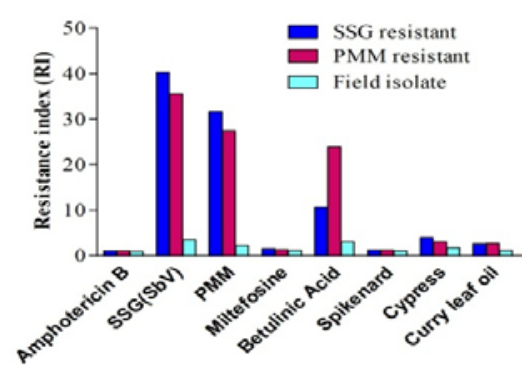

Fig. 2: Comparative study of resistance index (RI) of amphotericin B, sodium stibogluconate (SSG), paromomycin (PMM), miltefosine, betulinic acid, spikenard, cypress, curry leaf oil

Table 2: Drug sensitivity profiles against $L$. donovani wild-type, drug-resistant and field isolate axenic amastigote cell lines

\begin{tabular}{|c|c|c|c|c|c|c|c|}
\hline \multirow[t]{3}{*}{ Drug } & \multicolumn{7}{|c|}{$\mathrm{IC}_{50}($ mean $\pm S D, n=4) \mu \mathrm{M}^{\mathrm{a}}$} \\
\hline & \multicolumn{5}{|c|}{ Axenic AG83 evaluation model } & \multicolumn{2}{|c|}{ Axenic GE1 evaluation model } \\
\hline & Wild-type & SSG resistant $\mathbf{t}^{\mathbf{b}}$ & $\mathbf{R I}^{\mathbf{c}}$ & PMM resistant ${ }^{b}$ & $\mathbf{R I}^{\mathbf{c}}$ & Field isolate & $\mathbf{R I}^{\mathbf{d}}$ \\
\hline Amphotericin B & $0.27 \pm 0.02^{*}$ & $0.29 \pm 0.02^{*}$ & 1.07 & $0.30 \pm 0.03^{*}$ & 1.11 & $0.25 \pm 0.03^{*}$ & 0.92 \\
\hline $\mathrm{SSG}(\mathrm{SbV})^{\mathrm{e}}$ & $3.4 \pm 0.37$ & $137 \pm 15$ & 40.29 & $121 \pm 13.3$ & 35.58 & $12 \pm 1.6$ & 3.52 \\
\hline PMM & $12 \pm 1.56^{*}$ & $379 \pm 49.2^{*}$ & 31.58 & $329 \pm 39.5^{*}$ & 27.41 & $27 \pm 3.24^{*}$ & 2.25 \\
\hline Miltefosine & $0.42 \pm 0.06^{*}$ & $0.64 \pm 0.09^{*}$ & 1.52 & $0.54 \pm 0.07^{*}$ & 1.3 & $0.50 \pm 0.07^{*}$ & 1.2 \\
\hline
\end{tabular}

Data represented as mean $\pm S D, n=4$; the presented results are the average of four $(4)$ determinations, $I_{50}=50 \%$ inhibitory concentration, a $A s s a y s$ are described in Materials and Methods, bSSG and PMM resistant strains were sodium stibogluconate resistant strains and paromomycin resistant

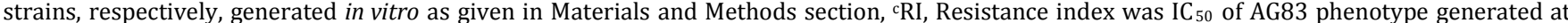
maximum drug pressure/IC ${ }_{50}$ of wild type, ${ }^{\mathrm{R} I}$, Resistance index was $\mathrm{IC}_{50}$ of field isolate/IC $\mathrm{I}_{50}$ of wild type, eValues for antimonial agent was in $\mu \mathrm{g}$ $\mathrm{Sb} / \mathrm{ml},{ }^{*} \mathrm{p}<0.001$, significant difference compared with SSG, ${ }^{* *} \mathrm{p}>0.01$, no significant difference compared with SSG. 
Table 3: Drug sensitivity profiles of intracellular amatigotes against wild-type, drug-resistant and field isolate L. donovani cell lines

\begin{tabular}{|c|c|c|c|c|c|c|c|c|c|}
\hline \multirow[t]{3}{*}{ Drug } & \multicolumn{8}{|c|}{$I_{50}($ mean $\pm S D, n=4) \mu M^{a}$} & \multirow{3}{*}{$\begin{array}{l}\text { Cytotoxicity } \mathrm{CC}_{50}(\mu \mathrm{M}) \\
\text { (Macrophage cells) }\end{array}$} \\
\hline & \multicolumn{6}{|c|}{ Cellular AG83 evaluation model } & \multicolumn{2}{|c|}{$\begin{array}{l}\text { Cellular GE1 } \\
\text { evaluation model }\end{array}$} & \\
\hline & $\begin{array}{l}\text { Wild- } \\
\text { type }\end{array}$ & $\mathbf{S I} \mathbf{I}^{\mathbf{c}}$ & $\begin{array}{l}\text { SSG } \\
\text { resistant }^{\mathrm{b}}\end{array}$ & SI $\mathbf{c}^{\mathrm{c}}$ & $\begin{array}{l}\text { PMM } \\
\text { resistant }^{\mathbf{b}}\end{array}$ & $\mathbf{S I}^{\mathbf{a}}$ & Field isolate & SI $\mathbf{c}^{\mathrm{c}}$ & \\
\hline Amphotericin & $0.18 \pm$ & 88.88 & $0.23 \pm 0.03^{*}$ & 69.56 & $0.24 \pm 0.03^{*}$ & 66.66 & $0.19 \pm 0.02^{*}$ & 84.21 & $16 \pm 2.1^{*}$ \\
\hline B & $0.02^{*}$ & & & & & & & & \\
\hline \multirow[t]{2}{*}{ SSG } & $2.1 \pm$ & 13.8 & $20.2 \pm 2.02$ & 1.4 & $18.3 \pm 2.19$ & 1.58 & $8.7 \pm 1.22$ & 3.33 & $29 \pm 4.35$ \\
\hline & 0.27 & & & & & & & & \\
\hline \multirow[t]{2}{*}{ PMM } & $8.4 \pm$ & 28.9 & $128.9 \pm 18.04^{*}$ & 1.88 & $117 \pm 11.7^{*}$ & 2.07 & $20.0 \pm 2.4^{*}$ & 12.15 & $243 \pm 29.76^{*}$ \\
\hline & $\begin{array}{l}1.1^{*} \\
0.36+\end{array}$ & 96 & $060+0 \cap 9^{*}$ & 575 & $046+0.05 *$ & 75 & $039+0.04^{*}$ & 885 & $345+448^{* *}$ \\
\hline Miltefosine & $0.05^{*}$ & & & & & 15 & $0.09 \pm 0.04$ & 0.5 & $34.3 \pm 4.40$ \\
\hline
\end{tabular}

Data represented as mean $\pm \mathrm{SD}, \mathrm{n}=4$; the presented results are the average of four (4) determinations, $\mathrm{IC}_{50}=50 \%$ inhibitory concentration, aAssays are described in Materials and Methods, bSSG and PMM resistant strains were sodium stibogluconate resistant strains and paromomycin resistant strains, respectively, generated in vitro as given in Materials and Methods section, 'Selectivity index SI was calculated by dividing the $\mathrm{CC}_{50}$ by IC $\mathrm{I}_{50}$, dValues for antimonial agent was in $\mu \mathrm{g} \mathrm{Sb} / \mathrm{ml},{ }^{*} \mathrm{p}<0.005$, significant difference compared with SSG, ${ }^{* *} \mathrm{p}>0.05$, no significant difference compared with SSG.

In process of drug development or drug discovery for any particular indication, the more crucial part is the balance between safety and efficacy of the drug candidate. The window between the safety and efficacy should be adequate enough to use them as a drug. Here comes the term selectivity index (SI). SI is an index which demonstrates the highest exposure to drug which should provide the highest efficacy with no toxicity. SI is calculated as $\mathrm{CC}_{50}$ of a drug/ $/ \mathrm{IC}_{50}$ of that drug. $50 \%$ Cellular Cytotoxicity $\left(\mathrm{CC}_{50}\right)$ is the concentration at which $50 \%$ of the cell population should be killed and $\mathrm{IC}_{50}$ is the $50 \%$ inhibitory concentration. It is considered that when SI value is equal to or more than 10 , the drug candidate have the promising activity for its intended purpose [38].

Table 4: Drug sensitivity profiles against $L$. donovani wild-type, drug-resistant and field isolate axenic amastigote cell lines

\begin{tabular}{|c|c|c|c|c|c|c|c|}
\hline \multirow[t]{3}{*}{ Drug } & \multicolumn{7}{|c|}{$\mathrm{IC}_{50}($ mean $\pm \mathrm{SD}, \mathrm{n}=4)\left[\mu \mathrm{M} / \mu \mathrm{I}^{\dagger}\right]^{\mathrm{a}}$} \\
\hline & \multicolumn{4}{|c|}{ Axenic AG83 evaluation model } & \multicolumn{3}{|c|}{ Axenic GEI evaluation model } \\
\hline & Wild-type & SSG resistant $\mathbf{b}^{\mathbf{b}}$ & $\mathbf{R I}^{\mathbf{c}}$ & PMM resistant ${ }^{b}$ & $\mathbf{R I}^{\mathbf{c}}$ & Field isolate & $\mathbf{R I}^{\mathbf{d}}$ \\
\hline Betulinic acid & $2 \pm 0.22^{*}$ & $21.2 \pm 2.33^{*}$ & 10.6 & $47.8 \pm 4.78^{*}$ & 23.9 & $6 \pm 0.6^{*}$ & 3 \\
\hline Spikenard oil ${ }^{\dagger}$ & $33 \pm 4.62^{*}$ & $42.5 \pm 5.95^{*}$ & 1.28 & $42.5 \pm 4.67^{*}$ & 1.28 & $35.5 \pm 4.26^{*}$ & 1.07 \\
\hline Cypress oil ${ }^{\dagger}$ & $11.5 \pm 1.49^{*}$ & $45.5 \pm 5.46^{*}$ & 3.96 & $35 \pm 3.85^{*}$ & 3.04 & $20 \pm 2.6^{*}$ & 1.74 \\
\hline Curry leaf oil ${ }^{\dagger}$ & $15 \pm 1.5^{*}$ & $39 \pm 5.85^{*}$ & 2.6 & $40 \pm 5.6^{*}$ & 2.66 & $18 \pm 2.16^{*}$ & 1.2 \\
\hline
\end{tabular}

Data represented as mean $\pm \mathrm{SD}, \mathrm{n}=4$; the presented results are the average of four (4) determinations, $\mathrm{IC}_{50}=50 \%$ inhibitory concentration, a ${ }^{2}$ sssays are described in Materials and Methods, ${ }^{\mathrm{b} S S G}$ and PMM resistant strains were generated in vitro as given in Materials and Methods, ${ }^{\mathrm{C} I}$, Resistance index was IC 50 of AG83 phenotype generated at maximum drug pressure/ $/ \mathrm{IC}_{50}$ of wild-type, ${ }^{\mathrm{d}} \mathrm{RI}$, Resistance index was $\mathrm{IC}_{50}$ of field isolate/IC 50 of wild type, eValues for antimonial agent was in $\mu \mathrm{g} \mathrm{Sb} / \mathrm{ml}$.

Table 5 and fig. 3 revealed that in case of cellular AG83 evaluation model, betulinic acid showed highest SI values which were 192.8 and 19.3 for wild-type and SSG resistant strains, respectively and highest in case of cellular GE1 evaluation model that was 100.

Whereas in case of PMM resistant strains, cypress showed highest SI value $(\mathrm{SI}=15.09)$. When the results against the cellular models of test drugs were compared to the standard drugs conventionally used for the treatment of visceral leishmaniasis, showed interesting results. Betulinic acid showed the highest activity against wild-type, SSG resistant and GE1 field isolated strains compared to all the standard drugs. From table 5 and fig. 4 it was also observed that cypress oil had the maximum $\mathrm{CC}_{50}$ value among all standard and tested drugs.

Table 5: Drug sensitivity profiles of intracellular amatigotes against wild-type, drug resistant and field isolate L. donovani cell lines

\begin{tabular}{|c|c|c|c|c|c|c|c|c|c|}
\hline \multirow[t]{3}{*}{ Drug } & \multicolumn{8}{|c|}{$I_{50}($ mean $\pm S D, n=4)\left[\mu M / \mu I^{+}\right]^{a}$} & \multirow{3}{*}{$\begin{array}{l}\text { Cytotoxicity } \mathrm{CC}_{50}\left(\mu \mathrm{M} / \mu \mathrm{l}^{\dagger}\right) \\
\text { (Macrophage cells) }\end{array}$} \\
\hline & \multicolumn{6}{|c|}{ Cellular AG83 evaluation model } & \multicolumn{2}{|c|}{$\begin{array}{l}\text { Cellular GE1 evaluation } \\
\text { model }\end{array}$} & \\
\hline & Wild-type & $\mathbf{S I} \mathbf{c}^{\mathbf{c}}$ & $\begin{array}{l}\text { SSG } \\
\text { resistant }\end{array}$ & SI & $\begin{array}{l}\text { PMM } \\
\text { resistant }^{b}\end{array}$ & $S \mathbf{I}^{\mathbf{a}}$ & Field isolate & SI ${ }^{c}$ & \\
\hline $\begin{array}{l}\text { Betulinic } \\
\text { acid }\end{array}$ & $1.4 \pm 0.15^{*}$ & 192.8 & $14 \pm 1.54^{*}$ & 19.3 & $32 \pm 3.84^{*}$ & 8.43 & $2.7 \pm 0.37^{*}$ & 100 & $270 \pm 27^{*}$ \\
\hline $\begin{array}{l}\text { Spikenard } \\
\text { oil }^{\dagger}\end{array}$ & $21.5 \pm 2.58^{*}$ & 17.67 & $31.5 \pm 3.15^{*}$ & 12.06 & $35 \pm 3.5^{*}$ & 10.85 & $29 \pm 3.19^{*}$ & 13.10 & $380 \pm 49.4^{*}$ \\
\hline Cypress oil ${ }^{\dagger}$ & $6.25 \pm 0.93^{*}$ & 72.46 & $30 \pm 3.3^{*}$ & 15.09 & $30 \pm 3.9^{*}$ & 15.09 & $13.0 \pm 1.69^{*}$ & 34.8 & $452.9 \pm 49.8^{*}$ \\
\hline $\begin{array}{l}\text { Curry leaf } \\
\text { oil }^{\dagger}\end{array}$ & $12.5 \pm 1.75^{*}$ & 18.8 & $24 \pm 2.88^{* *}$ & 9.79 & $26 \pm 3.12^{*}$ & 9.03 & $14.5 \pm 1.74^{*}$ & 16.2 & $235 \pm 30.5^{*}$ \\
\hline
\end{tabular}

Data represented as mean $\pm \mathrm{SD}, \mathrm{n}=4$; the presented results are the average of four (4) determinations, IC $50=50 \%$ inhibitory concentration, a Assays are described in Materials and Methods, bSSG and PMM resistant strains were generated in vitro as given in Materials and Methods, 'Selectivity index SI was calculated by dividing the $\mathrm{CC}_{50}$ by $\mathrm{IC}_{50}$, dValues for antimonial agent was in $\mu \mathrm{g}$ Sb/ml, ${ }^{*} \mathrm{p}<0.01$, significant difference compared with SSG, ${ }^{* *} p>0.05$, no significant difference compared with SSG. 


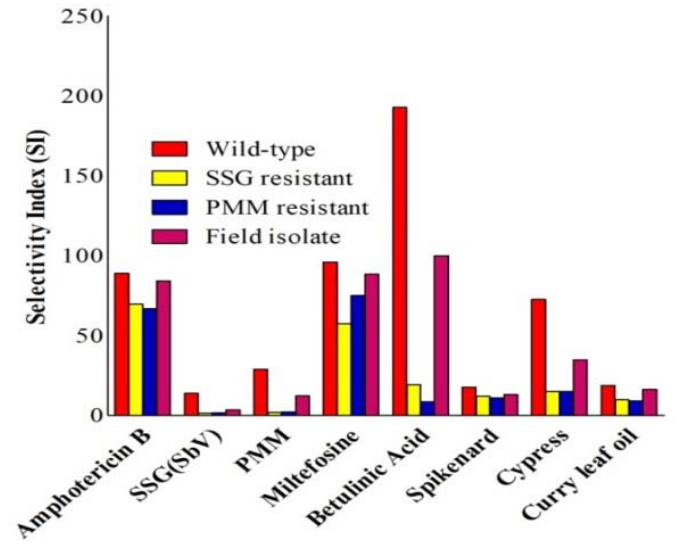

Fig. 3: Comparative study of selectivity index (SI) of amphotericin B, sodium stibogluconate (SSG), paromomycin (PMM), miltefosine, betulinic acid, spikenard, cypress, curry leaf oil

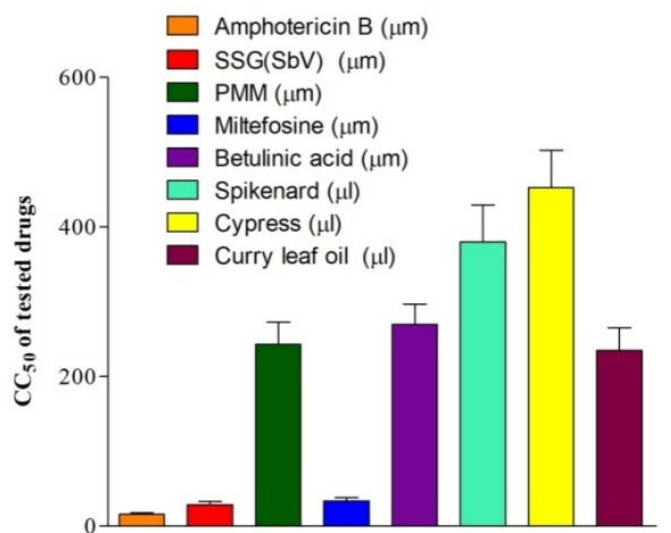

Fig. 4: $50 \%$ cellular cytotoxicity $\left(\mathrm{CC}_{50}\right)$ of amphotericin $\mathrm{B}$, sodium stibogluconate (SSG), paromomycin (PMM), miltefosine, betulinic acid, spikenard, cypress, curry leaf oil against isolated peritoneal macrophage cells. Data represented as mean $\pm S D, n=4$; the presented results are the average of four (4) determinations

\section{DISCUSSION}

To outwit the inadequacy of first-line antileishmanial agents is not only the major concern but conquering the emerging problem of drug resistance has high scientific importance in the field of leishmaniasis. To circumvent the hitch of drug resistance, searching for new drug candidate would be the smart approach in the current scenario for the treatment of visceral leishmaniasis.

Curry leaf oil, cypress oil, spikenard oil and betulinic acid had been selected for screening of antileishmanial activity. Curry leaf oil, cypress oil, spikenard oil were subjected to GC/MS analysis for the identification of the chemical components present and it was found that geranyl acetate $(32.55 \%$ peak area) and linalool $(21.16 \%$ peak area) were the chemical components majorly present in the curry leaf oil. Whereas in case of cypress oil, it was D-3-carene that acquired $21.35 \%$ peak area. D-cadinene $(24.53 \%$ peak area) and aristolene $(22.76 \%$ peak area) were the two components majorly present in spikenard oil.

The previous studies of the selected terpenoids have shown some interesting results. According to Singh et al. [42], the extracts obtained from the leaves of Murraya koenigii (Linn.), also known as Curry leaf have shown their antileishmanial activity against $L$. donovani promastigotes, however, we have generated the data for the curry leaf oil against $L$. donovani axenic as well as intracellular amastigotes. Similarly, when the extract of the cones of Taxodium distichum (Bald cypress) was evaluated for antileishmanial property,
Naman et al. [43] have generated the data against L. donovani promastigotes and amastigotes of L. amazonesis, whereas, we have evaluated the antileishmanial property of cypress oil against $L$. donovani axenic and intracellular amastigotes. A few significant data of the derivatives of betulinic acid have been found. According to Alakurtti et al. [44], a betulin derivatives which was the heterocycloadduct between 3,28-di-0-acetyllupa-12,18-diene and 4methylurazine have the $\mathrm{IC}_{50}$ of $8.9 \mu \mathrm{M}$ against $L$. donovani amastigotes. Chowdhury et al. [45] have published that synthesized betulin derivatives have been found to inhibit the growth of the parasite and it was also found that they can act by relaxing the activity of $L$. donovani topoisomerase I in a reversible manner. No significant data have been found for the antileishmanial activity of spikenard oil.

After reviewing the existing literatures, we have observed that sufficient data is lacking for the comparison of the antileishmanial activities of the selected plant derived terpenoids with that of the standard drugs available in the market. Therefore, in the present work, we have tested four terpenoids like betulinic acid, spikenard oil, cypress oil and curry leaf oil as potential drug candidates against SSG resistant, PMM resistant strains as well as AG83 wild type and GE1 field isolated strains. We have also compared the results of the tested drugs with the standard drugs like amphotericin B, sodium stibogluconate, paromomycin and miltefosine. Among all the tested drugs, betulinic acid showed highest resistance against SSG resistant and PMM resistant cell types (fig. 2). In fig. 2, it was also observed that amphotericin B, miltefosine, spikenard oil, cypress oil and curry leaf oil had almost similar and lowest resistance index than others which depicted that among the test drugs, spikenard oil and curry leaf oil were less resistant when it was compared with their effectiveness against wild type strains. Fig. 3 portrayed that betulinic acid was more effective against wild type, SSG-resistant and GE1 strains among all tested drugs.

The potential antileishmanial activity of betulinic acid might be due to the inhibition of topoisomerases of Leishmania spp. and also inducing apoptosis effect in the intracellular amastigotes of $L$. donovani as reported in earlier investigations [45]. Several studies are also reported for the antileishmanial properties of derivatives of betulinic acid [46, 47]. Therefore, further in vitro and in vivo investigations are required for the exploration of this lead compound with leismanicidal properties but nontoxic for the human host macrophages.

\section{CONCLUSION}

Since leishmaniasis is largely affecting human population worldwide and is responsible for high rates of morbidity and mortality, there is an urgent need for the search of novel antileishmanial agents. Newer drugs obtained from the plant sources could be a better alternative due to variations in their chemical constituents and fewer side effects. According to our present work, it could be concluded that betulinic acid and cypress oil could be the effective drug candidate against $L$. donovani mediated visceral leishmaniasis and all the four test drugs were significantly more effective than sodium stibogluconate and paromomycin against drug resistant Leishmania donovani strains. Moreover, this study further recommends the exploration of active chemical constituents in these terpenoids that are responsible for antieishmanial activity.

\section{ACKNOWLEDGEMENT}

We would like to show our gratitude to Dr. Shyamol Roy, Scientist, Indian Institute of Chemical Biology, Kolkata, India for his kind gift of Leishmania donovani AG83 and GE1 strains.

\section{AUTHORS CONTRIBUTIONS}

This research work was carried out in collaboration between all the five authors in the concept and design of the work, collection, assembly, analysis and interpretation of data, drafting the article, critical revision and approval of the final manuscript.

\section{CONFLICT OF INTERESTS}

There is no conflict of interest 


\section{REFERENCES}

1. Desjeux P. The increase in risk factors for the leishmaniasis Worldwide. Trans R Soc Trop Med Hyg 2001;95:239-43.

2. Ritting MG, Bogdan C. Leishmania host-cell interaction: complexities and alternative views. Parasitol Today 2000;16:292-7.

3. Santos DO, Countinho CER, Madeira MF. Leishmaniasis treatment-a challenge that remains: a review. Parasitol Res 2008;103:1-10.

4. Freitas Junior LH, Chatelain E, Kim HA, Siqueira Neto JL. Visceral leishmaniasis treatment: what do we have, what do we need and how to deliver it? Int J Parasitol: Drugs Drug Resist 2012;2:11-9.

5. Singh N, Kumar M, Singh RK. Leishmaniasis: current status of available drugs and new potential drug targets. Asian Pac J Trop Med 2012;5:485-97.

6. Croft SL, Sundar S, Fairlamb AH. Drug resistance in leishmaniasis. Clin Microbiol Rev 2006;19:111-26.

7. Banjara MR. Combination therapy for visceral leishmaniasis. Int J Infection Microbiol 2013;2:32-3.

8. Bakkali F, Averbeck S, Averbeck D, Idaomar M. Biological effects of essential oils-a review. Food Chem Toxicol 2008;46:446-75.

9. Alankar S. A review on peppermint oil. Asian J Pharm Clin Res 2009;2:27-33.

10. Rawat $P$, Khan MF, Kumar M, Tamarkar AK, Srivastava AK, Arya $\mathrm{KR}$, et al. Constituents from fruits of Cupressus sempervirens. Fitoterapia 2010;81:162-6.

11. Mascolo N, Autore G, Capasso F, Menghini A, Fasulo MP. Biological screening of Italian medicinal plants for antiinflammatory activity. Phytother Res 1987;1:28-31.

12. Selim SA, Adam ME, Hassan SM, Albalawi AR. Chemical composition, antimicrobial and antibiofilm activity of the essential oil and methanol extract of the Mediterranean cypress (Cupressus sempervirens L.). BMC Complementary Altern Med 2014;14:179.

13. Biswas AK, Chatli MK, Sahoo J. Antioxidant potential of curry (Murraya koenigii L.) and mint (Mentha spicata) leaf extracts and their effect on colour and oxidative stability of raw ground pork meat during refrigeration storage. Food Chem 2012;133:467-72

14. Nagappan T, Ramasamy P, Wahid ME, Segaran TC, Vairappan CS. Biological activity of carbazole alkaloids and essential oil of Murraya koenigii against antibiotic resistant microbes and cancer cell lines. Molecules 2011;16:9651-64.

15. Kesari AN, Gupta RK, Watal G. Hypoglycemic effects of Murraya koenigii on normal and alloxan-diabetic rabbits. J Ethnopharmacol 2005;97:247-51.

16. Sharma P, Vidyasagar G, Bhandari A, Singh S, Bhadoriya U, Ghule $S$, et al. A pharmacological evaluation of antidiarrhoeal activity of leaves extract of Murraya koenigii in experimentally induced diarrhoea in rats. Asian Pac J Trop Dis 2012;2:230-3.

17. Sathaye S, Bagul Y, Gupta S, Kaur H, Redkar R. Hepatoprotective effects of aqueous leaf extract and crude isolates of Murraya koenigii against in vitro ethanol-induced hepatotoxicity model. Exp Toxicol Pathol 2011;63:587-91.

18. Nakamura S, Nakashima S, Oda Y, Yokota N, Fujimoto K, Matsumoto T, et al. Alkaloids from Sri Lankan curry-leaf (Murraya koenigii) display melanogenesis inhibitory activity: structures of karapinchamines A and B. Bioorg Med Chem 2013;21:1043-9.

19. Birari R, Javia V, Bhutani KK. Antiobesity and lipid lowering effects of Murraya koenigii (L.) Spreng leaves extracts and mahanimbine on high fat diet induced obese rats. Fitoterapia 2010;81:1129-33.

20. Takemoto H, Ito M, Shiraki T, Yagura T, Honda G. Sedative effects of vapor inhalation of agarwood oil and spikenard extract and identification of their active components. J Nat Med 2008;62:41-6.

21. Agnihotri S, Wakode S, Ali M. Chemical composition, antimicrobial and topical anti-inflammatory activity of Valeriana jatamansi Jones essential oil. J Essen Oil Bearing Plants 2011;14:417-22.

22. Mathew M, Subramanian S. In vitro screening for anticholinesterase and antioxidant activity of methanolic extracts of ayurvedic medicinal plants used for cognitive disorders. PLoS One 2014;9:e86804.

23. Razack S, Khanum F. Anxiolytic effects of Nardostachys jatamansi DC in mice. Ann Phytomed 2012;1:67-73.

24. Khan MB, Hoda MN, Ishrat T, Ahmad S, Khan MM, Ahmad A, et al. Neuroprotective efficacy of Nardostachys jatamansi and crocetin in conjunction with selenium in cognitive impairment. Neurol Sci 2012;33:1011-20.

25. Chaudhary S, Chandrashekar KS, Pai KS, Setty MM, Devkar RA, Reddy ND, et al. Evaluation of antioxidant and anticancer activity of extract and fractions of Nardostachys jatamansi DC in breast carcinoma. BMC Complementary Altern Med 2015;15:50.

26. Aleem MA, Asad BS, Mohammed T, Khan RA, Ahmed MF, Anjum $A$, et al. Antidiabetic activity of hydroalcoholic extracts of Nardostachys jatamansi in alloxan-induced diabetic rats. $\mathrm{Br} \mathrm{J}$ Med Med Res 2014;4:4665-73.

27. Sandeep PM, Bovee TF, Sreejith K. Anti-androgenic activity of Nardostachys jatamansi DC and Tribulus terrestris L. and their beneficial effects on polycystic ovary syndrome-induced rat models. Metab Syndr Relat Disord 2015;13:248-54.

28. Yogeeswari P, Sriram D. Betulinic acid and its derivatives: a review on their biological properties. Curr Med Chem 2005;12:657-66.

29. Chandramu C, Manohar RD, Krupadanam DG, Dashavantha RV. Isolation, characterization and biological activity of betulinic acid and ursolic acid from Vitex negundo L. Phytother Res 2003;17:129-34.

30. Domínguez-Carmona DB, Escalante-Erosa F, García-Sosa K, Ruiz-Pinell G, Gutierrez-Yapu D, Chan-Bacab MJ, et al. Antiprotozoal activity of betulinic acid derivatives. Phytomedicine 2010;17:379-82.

31. Pavlova NI, Savinova OV, Nikolaeva SN, Boreko EI, Flekhter OB. Antiviral activity of betulin, betulinic and betulonic acids against some enveloped and non-enveloped viruses. Fitoterapia 2003;74:489-92.

32. Mullauer FB, Kessler JH, Medema JP. Betulinic acid, a natural compound with potent anticancer effects. Anticancer Drugs 2010;2:215-27.

33. Yun $\mathrm{Y}$, Han $\mathrm{S}$, Park E, Yim D, Lee $\mathrm{S}$, Lee $\mathrm{CK}$, et al. Immunomodulatory activity of betulinic acid by producing proinflammatory cytokines and activation of macrophages. Arch Pharm Res 2003;26:1087-95.

34. Bori ID, Hung HY, Qian K, Chen CH, Morris-Natschke SL, Lee KH. Anti-AIDS agents 88 Anti-HIV conjugates of betulin and betulinic acid with AZT prepared via click chemistry. Tetrahedron Lett 2012;53:1987-9.

35. Manjamalai A, Narala Y, Haridas A, Grace VB. Antifungal, antiinflammatory and GC-MS analysis of methanolic extract of Plectranthus amboinicus leaf. Int I Curr Pharm Res 2011;3:129-36.

36. Roy P, Das S, Bera T, Mondal S, Mukherjee A. Andrographolide nanoparticles in leishmaniasis: characterization and in vitro evaluations. Int J Nanomed 2010;5:1113-21.

37. Das S, Roy P, Mondal S, Bera T, Mukherjee A. One pot synthesis of gold nanoparticles and application in chemotherapy of wild and resistant type visceral leishmaniasis. Colloids Surf B 2013;107:27-34.

38. Ghosh S, Das S, De AK, Kar N, Bera T. Amphotericin B-loaded mannose modified poly (D, L-lactide-co-glycolide) polymeric nanoparticles for the treatment of visceral leishmaniasis: in vitro and in vivo approaches. RSC Adv 2017;7:29575-90.

39. Ghosh S, Kar N, Bera T. Oleanolic acid loaded poly lactic coglycolic acidvitamin E TPGS nanoparticles for the treatment of Leishmania donovani infected visceral leishmaniasis. Int J Biol Macromol 2016;93:961-70.

40. Mondal S, Roy P, Das S, Halder A, Mukherjee A, Bera T. In vitro susceptibilities of wild and drug resistant Leishmania donovani amastigote stages to andrographolide nanoparticle: role of vitamin e derivative TPGS for nanoparticle efficacy. Plos One 2013;8:e81492

41. Nwaka S, Hudson A. Innovative lead discovery strategies for tropical diseases, Nat Rev Drug Discovery 2006;5:941-55.

42. Singh SK, Bimal S, Narayan S, Jee C, Bimal D, Das P, et al. Leishmania donovani: assessment of leishmanicidal effects of herbal extracts obtained from plants in the visceral leishmaniasis endemic area of Bihar, India. Exp Parasitol 2011;127:552-8. 
43. Naman CB, Gromovsky AD, Vela CM, Fletcher JN, Gupta G, Varikuti S, et al. Antileishmanial and cytotoxic activity of some highly oxidized abietane diterpenoids from the bald cypress, Taxodium distichum. J Nat Prod 2016;79:598-606.

44. Alakurtti S, Heiska T, Kiriazis A, Sacerdoti-Sierra N, Jaffe CL, YliKauhaluoma J. Synthesis and anti-leishmanial activity of heterocyclic betulin derivatives. Bioorganic Med Chem 2010;18:1573-82.

45. Chowdhury S, Mukherjee T, Sengupta S, Chowdhury SR, Mukhopadhyay S, Majumder HK. Novel betulin derivatives as antileishmanial agents with mode of action targeting type IB DNA topoisomerase. Mol Pharmacol 2011;80:694-703.

46. Wert L, Alakurtti S, Corral MJ, Sánchez-Fortún S, YliKauhaluoma J, Alunda JM. Toxicity of betulin derivatives and in vitro effect on promastigotes and amastigotes of Leishmania infantum and L. donovani. J Antibiot 2011;64:475.

47. Sousa MC, Varandas R, Santos RC, Santos-Rosa M, Alves V, Salvador JA. Antileishmanial activity of semisynthetic lupane triterpenoids betulin and betulinic acid derivatives: synergistic effects with miltefosine. PLOS One 2014;9:e89939. 